\title{
PROBLEMAS EN TORNO A LA VISUALIZACIÓN DE LA CUESTIÓN AMBIENTAL EN MEDIOS DE CIRCULACIÓN MASIVA: Las Imágenes del Cambio Climático en la Revista Viva (1994-2010)
}

\section{THE PROBLEMATIC STATUS OF VISUALIZING ENVIRONMENTAL ISSUES IN MEDIA: Images of Climatic Change In An Argentinean Magazine}

\author{
Dra. Verónica Hollman \\ Investigadora CONICET- Centro de Investigaciones Geográficas \\ Profesora Universidad Nacional del Centro de la Provincia de Buenos Aires.
}

\section{RESUMEN}

Proponemos analizar el papel que desempeñan las imágenes en nuestras formas de pensar e imaginar la naturaleza, particularmente aquellas que circulan en forma masiva y que conforman el campo de los saberes geográficos no académicos. Para ello, examinamos las imágenes del cambio climático publicadas en la revista Viva durante el período 1994-2010. Indagamos las formas de hacer ver el cambio climático que se despliegan, las claves visuales que se articulan con recurrencia y el estatus asignado a los géneros de imágenes utilizados. También identificamos las dificultades que se presentan a la hora de otorgar visibilidad al cambio climático para pensar desde una perspectiva más amplia la comunicación visual de la temática ambiental.

PALABRAS CLAVES: cultura visual; cambio climático; medios de comunicación; imágenes.

\section{ABSTRACT}

We propose to analyze the images of climatic change published in an Argentinean magazine (19942010) with the assumption that they can offer interesting elements to understand the relationship between visual culture and the social construction of nature. We identify different ways of visualizing climatic change as well as the status claimed for the images used. Finally, we discuss the problematic status of climatic change in order to rethink the visual communication of environmental issues.

KEYWORDS: visual culture; climatic change; media; images.

\section{SUMARIO}

Introducción

El cambio climático en la agenda de los medios de comunicación masiva: el caso de la Revista Viva (1994-2010)

Hacer ver el cambio climático

Algunas conclusiones para re-pensar la comunicación visual de la cuestión ambiental

Publicado en formato digital: Dra. Verónica Hollman. PROBLEMAS EN TORNO A LA VISUALIZACIÓN DE LA CUESTIÓN AMBIENTAL EN MEDIOS DE CIRCULACIÓN MASIVA: Las Imágenes del Cambio Climático en la Revista Viva (1994-2010). Revista Geográfica Digital. IGUNNE. Facultad de Humanidades. UNNE. Año 10. № 19. Enero - Junio 2013. ISSN 1668-5180 Resistencia, Chaco. En:

http://hum.unne.edu.ar/revistas/geoweb/default.htm 


\section{INTRODUCCIÓN}

Our ways of thinking about the natural world are powerfully shaped by our time, our place, and our culture. William Cronon, 1996: 35

Desde la década de 1960, en distintas partes del mundo, particularmente en Estados Unidos y en las naciones europeas occidentales, se fue configurando un movimiento cultural que compartía una creciente preocupación en torno a la protección de la naturaleza (Cronon, 1996). En efecto, desde una perspectiva diacrónica, podríamos trazar una verdadera revolución en los modos de concebir las transformaciones de la naturaleza: de signo de emancipación del dominio que la naturaleza le imponía a la sociedad en los siglos XVIII y XIX (Harvey, 1996) a una amenaza para la vida social a partir de la segunda década del siglo XX. Así, un conjunto de temáticas tales como la extinción de especies, la contaminación del agua, el aire y el suelo, la tala de bosques comenzaron a ingresar en la agenda de los medios periodísticos, publicidades, campañas de organizaciones ambientales, documentales y películas.

Numerosos trabajos han explorado cómo la cultura, en un tiempo histórico y lugar determinado, moldea nuestra percepción, conceptualización y representación de la naturaleza (Williams, 1980; Portogonçalves, 1990; Cronon, 1996; Santos, 1996). Sin embargo, la revisión de la literatura permite advertir dos campos, todavía poco investigados, que brindarían sugerentes aportes desde la Geografía Cultural. El primero es la producción y circulación de significados y percepciones sociales sobre la naturaleza y su transformación en los medios de comunicación (Anderson, 1997). El segundo, es la participación de las imágenes en la construcción de nuestras concepciones y percepciones de la naturaleza (1). Las imágenes en circulación en los medios de comunicación han documentado los efectos negativos de la transformación de la naturaleza y entrenado nuestros ojos para mirar con "lentes" ambientales la producción social de la naturaleza. De allí el interés que despierta analizar la participación de las imágenes en nuestras formas de pensar e imaginar la naturaleza, particularmente aquellas que circulan en forma masiva y que conforman el campo de los saberes geográficos no académicos (2).

El cambio climático ingresó más tardíamente en la agenda ambiental de los medios de comunicación masiva en Argentina. No obstante, la difusión de información a través de los medios de comunicación ha sido clave en la identificación y reconocimiento del cambio climático como un problema central de la agenda ambiental. Sin duda, los lectores recordarán escenas cotidianas en las cuales personas de edades y formaciones diversas citan el cambio climático como la explicación verdadera y científica para eventos climáticos de variada escala, magnitud e intensidad.

Desde una perspectiva cultural, proponemos examinar las formas de visualización del cambio climático desplegadas en Viva, una revista que se distribuye en la edición del día domingo del diario Clarín y que se dirige a un público amplio y diverso. Algunos de los interrogantes que articulan esta indagación son los siguientes: ¿Cómo ingresa el cambio climático en la agenda ambiental de la revista Viva? ¿Qué géneros de imágenes se utilizan para mostrar el cambio climático en los medios de comunicación? ¿Qué claves visuales se articulan con recurrencia para difundir y explicar el cambio climático? ¿Cuáles son las dificultades que se presentan a la hora de otorgar visibilidad el cambio climático en los medios de comunicación en Argentina? Finalmente, nos preguntamos qué nos autorizan/ impiden ver estas imágenes y cómo nos posicionamos ante ellas, entendiendo que las formas de visualización son dispositivos políticos en tanto constituyen "formas de construcción del mundo que vivimos" (Arfuch, 2006: 84).

Publicado en formato digital: Dra. Verónica Hollman. PROBLEMAS EN TORNO A LA VISUALIZACIÓN DE LA CUESTIÓN AMBIENTAL EN MEDIOS DE CIRCULACIÓN MASIVA: Las Imágenes del Cambio Climático en la Revista Viva (1994-2010). Revista Geográfica Digital. IGUNNE. Facultad de Humanidades. UNNE. Año 10. № 19. Enero - Junio 2013. ISSN 1668-5180 Resistencia, Chaco. En:

http://hum.unne.edu.ar/revistas/geoweb/default.htm 


\section{EL CAMBIO CLIMÁTICO EN LA AGENDA DE LOS MEDIOS DE COMUNICACIÓN MASIVA: EL CASO DE VIVA (1994-2010)}

Viva se destaca en el universo de revistas argentinas en función de la cantidad de ejemplares en circulación (Ver Cuadro 1). Sus lectores son catalogados en el mundo del marketing como multitarget: la revista constituye un valioso espacio para la promoción de productos de amplio espectro. Su registro temático, el diseño y la edición de los textos periodísticos se articulan para promover una lectura fácil y amena. Es una revista para "ver, pensar y sentir", según se enuncia desde la editorial, característica que se evidencia en un variado conjunto de secciones: entretenimiento - humor gráfico, juegos de ingenio-, actualidad - cultura, tecnología, salud, ambiente, viajes- y otras aún más variadas como el horóscopo semanal, recetas de cocina, moda y belleza.

La revista se distribuye con la edición en papel del día domingo del diario Clarín y su contenido no está disponible on-line. El diseño y el acceso exclusivo a través del formato papel convocan a una modalidad de lectura que se asemeja a un recorrido visual. Cabe destacar que es frecuente encontrar esta revista en ámbitos donde se realiza una lectura casual, con una extensión temporal variable, como en salas de espera de consultorios y en las mesas de los bares. Pero también, según lo indican las cartas de lectores publicadas en la revista, algunos de los artículos publicados ingresan al campo de los saberes legitimados por la escuela pues los docentes (lectores de la revista) los utilizan como material de lectura para sus clases.

Cuadro 1: Circulación neta pagada de revistas semanales. Promedios por edición del mes de Julio 2012 expresados en ejemplares.

\begin{tabular}{|l|l|}
\hline REVISTA & Cantidad \\
\hline Viva & 606.758 \\
\hline La Nación Revista & 359.818 \\
\hline Paparazzi & 95.351 \\
\hline Pronto Semanal & 93.654 \\
\hline Genios & 65.679 \\
\hline Billiken & 57.268 \\
\hline Caras & 53.348 \\
\hline Ñ Revista de Cultura Clarín & 38.475 \\
\hline El Gráfico & 26.788 \\
\hline National Geographic & 17.570 \\
\hline
\end{tabular}

Elaboración propia. Fuente: Estadísticas del Instituto Verificador de Circulaciones disponibles en: http://www.ivc.org.ar/consulta

El diseño asume un rol clave en la búsqueda constante de la combinación de informar y entretener. El tema central se expone en la tapa con una imagen que ocupa prácticamente toda la página de apertura y un título que orienta al lector; también algunas de las notas complementarias se presentan con titulares en los márgenes superior o inferior de la tapa.

Los primeros temas ambientales que se desarrollan en Viva toman la ciudad de Buenos Aires y su área metropolitana como ámbito de referencia (3). Así, se presentan como problemas ambientales

Publicado en formato digital: Dra. Verónica Hollman. PROBLEMAS EN TORNO A LA VISUALIZACIÓN DE LA CUESTIÓN AMBIENTAL EN MEDIOS DE CIRCULACIÓN MASIVA: Las Imágenes del Cambio Climático en la Revista Viva (1994-2010). Revista Geográfica Digital. IGUNNE. Facultad de Humanidades. UNNE. Año 10. № 19. Enero - Junio 2013. ISSN 1668-5180 Resistencia, Chaco. En:

http://hum.unne.edu.ar/revistas/geoweb/default.htm 
temáticas directamente relacionadas con la calidad de vida de sus ciudadanos: contaminación de cursos de agua, contaminación atmosférica, la existencia de niveles excesivos de ruido, la construcción de autopistas cerca de las viviendas, la acumulación de basura, etc. A partir del año 1996 la agenda ambiental inicia una diversificación tanto temática como en las escalas geográficas seleccionadas. Si tomamos como indicador la frecuencia de aparición, Viva otorga mayor relevancia a los siguientes temas en el período bajo análisis:

-Escala global: la variabilidad climática, el crecimiento demográfico bajo la categorización de "superpoblación", el adelgazamiento de la capa de ozono categorizado como "agujero de ozono".

-Escala regional: la posible contaminación del río Uruguay por la instalación de plantas de celulosa de papel, la apropiación privada de paisajes concebidos como paraísos naturales, la existencia de ecosistemas únicos en peligro, la calidad del agua para consumo.

-Escala local: la contaminación del Riachuelo.

El cambio climático ingresa en la agenda ambiental de la revista a partir del año 1998 asociado a dos temáticas: la corriente del niño y la reducción de la capa de ozono (Ver Cuadro 2). Los artículos explican el carácter natural de la corriente del niño pero destacan que la intensificación de sus efectos estaría vinculada al cambio climático. En tanto, la reducción de la capa de ozono se explica como una consecuencia directa de la creciente emisión de CFC provenientes de equipos de refrigeración, heladeras, aerosoles, etcétera. La tendencia de tomar eventos particulares y asociarlos al cambio climático se mantiene durante todo el período bajo análisis. No obstante, a partir del año 2001, el cambio climático asume el carácter de problema ambiental con entidad propia al presentarse como nota de tapa de la revista en dos oportunidades (4).

Cuadro 2: El cambio climático en la agenda ambiental de la Revista Viva (1994-2010)

\begin{tabular}{|l|l|l|}
\hline $\begin{array}{l}\text { Temáticas abordadas del } \\
\text { cambio climático }\end{array}$ & $\begin{array}{l}\text { Año de } \\
\text { Publicación }\end{array}$ & $\begin{array}{l}\text { Secciones en las que se } \\
\text { presenta }\end{array}$ \\
\hline $\begin{array}{l}\text { Desastres naturales asociados al } \\
\text { cambio climático }\end{array}$ & 2005 & Artículo \\
2005 & Artículo \\
Foto-reportaje & Foto-reportaje \\
\hline "Agujero" Ozono & 2008 & Humor \\
& 1998 & Infografía \\
Variabilidad & 1999 & Artículo \\
climático & 2001 & Tapa y artículo \\
& 2002 & Artículo \\
& 1998 & Artículo \\
& 1998 & Artículo \\
& 1999 & Tapa y Artículo \\
& 2001 & Artículo \\
& 2004 & Artículo \\
& 2006 & Tapa y Artículo \\
\hline
\end{tabular}

Elaboración propia. Fuente: Revistas Viva 1994-2010

Publicado en formato digital: Dra. Verónica Hollman. PROBLEMAS EN TORNO A LA VISUALIZACIÓN DE LA CUESTIÓN AMBIENTAL EN MEDIOS DE CIRCULACIÓN MASIVA: Las Imágenes del Cambio Climático en la Revista Viva (1994-2010). Revista Geográfica Digital. IGUNNE. Facultad de Humanidades. UNNE. Año 10. № 19. Enero - Junio 2013. ISSN 1668-5180 Resistencia, Chaco. En:

http://hum.unne.edu.ar/revistas/geoweb/default.htm 
La Figura 1, tapa de la edición del 25 de Febrero del año 2007, advierte la centralidad que asume la imagen para dar a conocer el cambio climático a una audiencia amplia y diversa. En la próxima sección analizaremos con mayor detenimiento esta imagen; aquí queremos destacar las implicancias asociadas a la presentación del cambio climático como artículo central de la revista. La imagen de tapa de la revista, en función del lugar de publicación y su diseño, busca capturar la mirada de todos los lectores y de este modo, invitarlos a dirigirse al artículo de referencia. Las cartas de lectores publicadas en la revista son elocuentes en lo que respecta a las implicancias del lugar otorgado al tema en la revista:

"Quería felicitarlos por la nota sobre el calentamiento y por haberla puesto como tapa. Creo que es la manera de concientizar a los argentinos que el cambio climático es una realidad y que todos somos parte de ella" (Viva, 11 Marzo 2007).

Figura 1: El cambio climático como nota de tapa

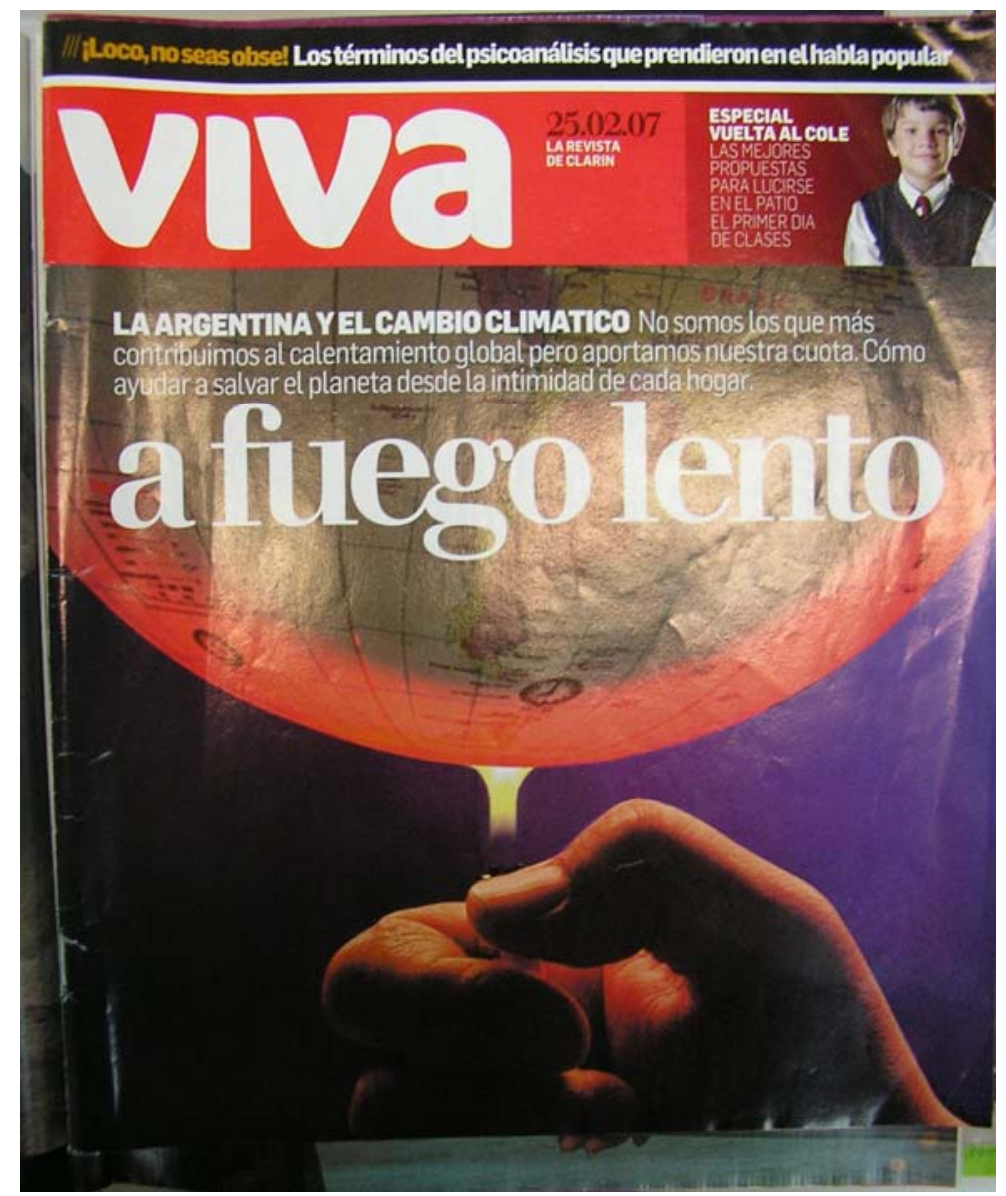

Fuente: "A fuego lento". Viva 25 de Febrero 2007. Gentileza Hemeroteca Biblioteca Nacional.

\section{HACER VER EL CAMBIO CLIMÁTICO}

Investigaciones previas han identificado tres problemas en la cobertura de temas ambientales por parte de los medios de comunicación masivos (Anderson, 1997). En primer lugar, el contenido científico y técnico de los temas ambientales impone un proceso de simplificación para una audiencia

Publicado en formato digital: Dra. Verónica Hollman. PROBLEMAS EN TORNO A LA VISUALIZACIÓN DE LA CUESTIÓN AMBIENTAL EN MEDIOS DE CIRCULACIÓN MASIVA: Las Imágenes del Cambio Climático en la Revista Viva (1994-2010). Revista Geográfica Digital. IGUNNE. Facultad de Humanidades. UNNE. Año 10. № 19. Enero - Junio 2013. ISSN 1668-5180 Resistencia, Chaco. En:

http://hum.unne.edu.ar/revistas/geoweb/default.htm 
Revista Geográfica Digital. IGUNNE. Facultad de Humanidades. UNNE. Año 10. № 19. Enero - Junio 2013. ISSN 1668-5180 Resistencia, Chaco

no especializada. Esta simplificación es un proceso complejo que no siempre es realizado por periodistas especializados. El segundo problema consiste en la tendencia a priorizar la cobertura de eventos de carácter puntual y dramático y por consiguiente, la exclusión de la agenda periodística de procesos de largo plazo (cuyos efectos son escasamente visibles). Finalmente, en una cultura como la occidental que ha canonizado que es necesario ver para creer (Doyle, 2009) y ver como sinónimo de conocer (Oliveira Jr., 2009), los medios de comunicación requieren un fuerte componente visual para transmitir la información. Cabe indagar, entonces, las estrategias visuales desplegadas desde los medios de comunicación para hacernos ver el cambio climático.

Ya en 1997, uno de los periodistas entrevistados en una investigación sobre las formas de comunicación de los temas ambientales en la prensa inglesa señalaba que "las historias ambientales realmente necesitan imágenes efectivas.... El calentamiento global es muy difícil de mostrar porque realmente no se puede ver" (Anderson, 1997: 122). En efecto, el cambio climático es un fenómeno no asequible a los ojos (5). A la hora de pensar la comunicación del cambio climático y sus niveles de efectividad se impone el siguiente interrogante: ¿Cómo hacer visible esta temática ambiental y provocar en las audiencias un mirar comprometido? En esta sección examinaremos las estrategias visuales que se han articulado desde la revista Viva con la finalidad de hacer ver el cambio climático.

La utilización recurrente de imágenes del globo terrestre para hacer visible el cambio climático ya ha sido identificada en una investigación sobre las formas de visualizar el cambio climático en la televisión (Lester et al, 2009). La Figura 1 es representativa de la introducción de esta forma de hacer ver el cambio climático en Viva. La imagen nos deja ver una parte del globo terráqueo sometida al calor que es provocado por un encendedor sostenido por una mano. Se presentan tres claves visuales cuya interpretación requiere apelar a elementos de una memoria visual y a cierto grado de conocimiento sobre el cambio climático. Primera clave visual: las crecientes posibilidades técnicas de captura de imágenes de la Tierra desde el espacio y de publicación han facilitado la incorporación en nuestra memoria visual el planeta Tierra como un globo visto desde afuera (Cosgrove, 1994). Segunda y tercera clave visual: el encendedor y la mano suponen algún grado de información sobre una de las posibles causas del cambio climático. El título y el breve texto de la tapa interactúan con estas claves visuales y permiten que los lectores menos involucrados en la temática puedan interpretarlas. La imagen simplifica la complejidad de la temática del cambio climático al mostrar solo una de sus aristas: el aumento de la temperatura.

La imagen educa nuestros ojos para que miremos el carácter social y global del cambio climático. La imagen nos hace tomar una posición: ciudadanos globales en igualdad de condiciones respecto a los niveles de responsabilidad y acción. Las cartas publicadas a posteriori de esta nota permiten identificar este posicionamiento en los lectores:

"Los felicito por este tipo de notas que ayudan a tomar conciencia del daño que le hacemos a nuestro planeta". (Viva, 11 Marzo 2007)

"Hay una gran cantidad de cosas de la vida cotidiana que muchas veces no advertimos y que nos parecen insignificantes, pero si cada uno comienza a tomar conciencia de los efectos de las acciones y omisiones que realizamos a diario, podemos aportar nuestro granito de arena para frenar los efectos del calentamiento". (Viva, 11 Marzo 2007)

Otra forma de hacer ver el cambio climático en Viva consiste en apelar al género fotográfico como registro/documento de eventos climáticos de gran magnitud e intensidad y sus efectos sociales huracanes, inundaciones, sequías, etc.-. Las fotografías seleccionadas capturan y exhiben escenas dramáticas: campos inundados, suelos totalmente agrietados ante sequías extraordinarias, primeros planos de personas angustiadas ante la destrucción de sus viviendas, etcétera (6). El conjunto de estas imágenes combina miradas desde lo alto -fotografías aéreas que permiten tener una idea más acabada de la magnitud de los impactos- y miradas muy cercanas de los rostros de las personas afectadas. Se trata de escenas que nuestra memoria visual reconoce con facilidad pues la producción

Publicado en formato digital: Dra. Verónica Hollman. PROBLEMAS EN TORNO A LA VISUALIZACIÓN DE LA CUESTIÓN AMBIENTAL EN MEDIOS DE CIRCULACIÓN MASIVA: Las Imágenes del Cambio Climático en la Revista Viva (1994-2010). Revista Geográfica Digital. IGUNNE. Facultad de Humanidades. UNNE. Año 10. № 19. Enero - Junio 2013. ISSN 1668-5180 Resistencia, Chaco. En:

http://hum.unne.edu.ar/revistas/geoweb/default.htm 
y circulación de imágenes de eventos climáticos extremos se ha multiplicado con las nuevas tecnologías de la información y comunicación (7).

Analicemos esta modalidad de visualización del cambio climático a través de la Figura 2. La fotografía captura un instante del paso de un huracán en Florida, Estados Unidos. El epígrafe, con fondo rojo, señala el contexto de dramatismo con una leyenda que indica que el huracán provocó 1500 muertos en Haití. La fotografía no muestra el cambio climático; tampoco constituye una prueba de la existencia de una relación directa entre los eventos climáticos extremos -desarrollo, frecuencia y magnitud- y el cambio climático. Sin embargo, el realismo de las escenas capturadas opera como evidencia probatoria del cambio climático y el aura de verdad que goza la fotografía, particularmente el fotoperiodismo, termina borrando la controversia que se enuncia desde el mismo texto. Como señala Susan Sontag, "En una era de sobrecarga de informativa, la fotografía ofrece un modo expedito de comprender algo y un medio compacto de memorizarlo. La fotografía es como una cita, una máxima o un proverbio" (Sontag, 2003:31).

Las fotografías de los efectos de eventos climáticos extremos educan nuestros ojos para mirar el cambio climático en dos sentidos: por un lado hacen ver un escenario hipotético como una realidad inobjetable; por otro, van conformando parte de nuestra memoria visual y convierten en familiar algo extraordinario, inédito, extremo y hasta hipotético.

Figura 2: Hacer ver los efectos de eventos climáticos de gran magnitud como efectos del cambio climático

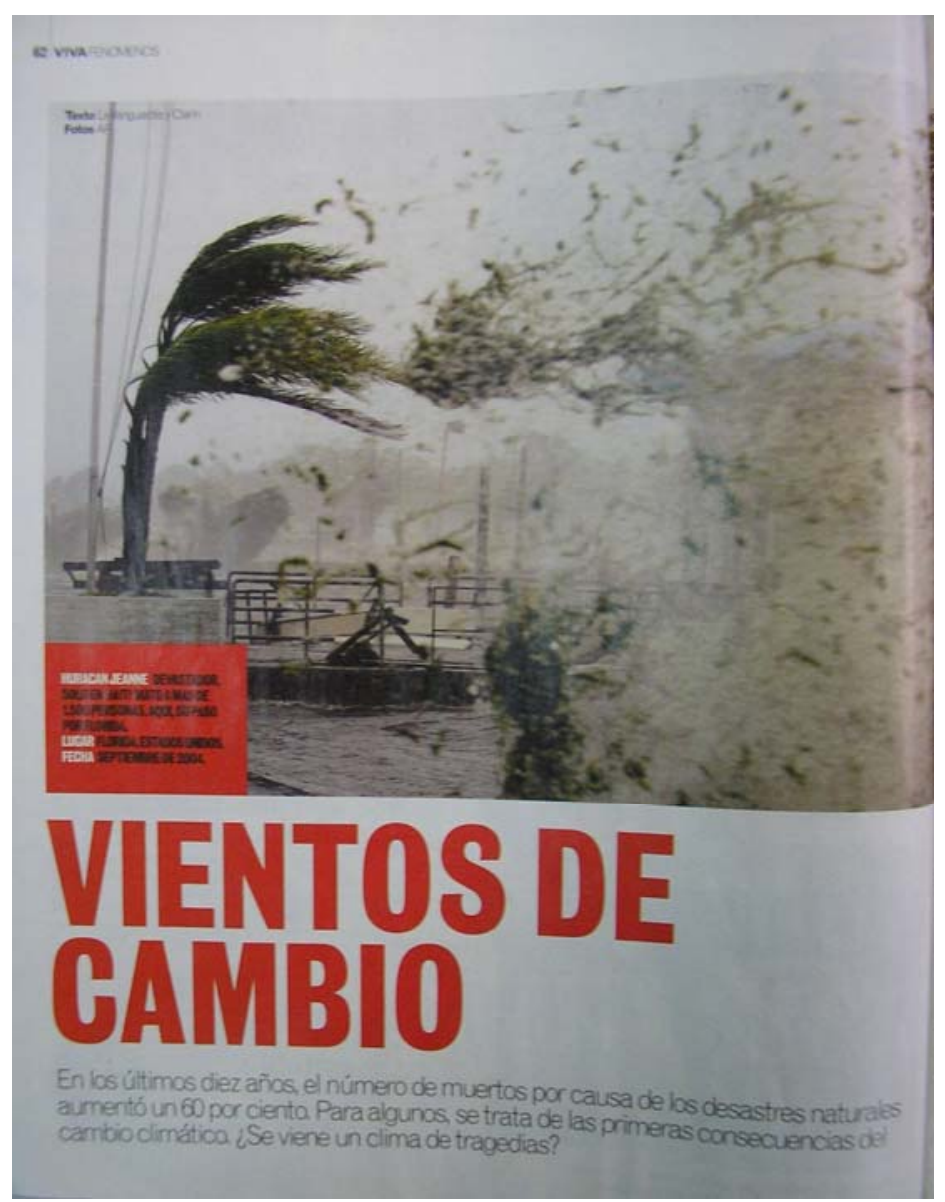

Fuente: "Vientos de cambio". Viva 12 de Diciembre 2004. Gentileza Hemeroteca Biblioteca Nacional.

Publicado en formato digital: Dra. Verónica Hollman. PROBLEMAS EN TORNO A LA VISUALIZACIÓN DE LA CUESTIÓN AMBIENTAL EN MEDIOS DE CIRCULACIÓN MASIVA: Las Imágenes del Cambio Climático en la Revista Viva (1994-2010). Revista Geográfica Digital. IGUNNE. Facultad de Humanidades. UNNE. Año 10. № 19. Enero - Junio 2013. ISSN 1668-5180 Resistencia, Chaco. En:

http://hum.unne.edu.ar/revistas/geoweb/default.htm 
Revista Geográfica Digital. IGUNNE. Facultad de Humanidades. UNNE. Año 10. № 19. Enero - Junio 2013.

ISSN 1668-5180 Resistencia, Chaco

Viva también apela a la utilización de imágenes que en sí mismas gozan de un estatus científico, como los mapas y las imágenes satelitales para hacer visible el cambio climático (8). Ambos géneros de imágenes nos ofrecen una visión que no podríamos lograr en forma directa: una visión desde lo alto, una visión sintética. También, la producción de ambos géneros de imágenes comprende un conjunto de decisiones y operaciones de selección que por su carácter técnico quedan fuera de discusión para sus usuarios. La introducción de estos dos géneros de imágenes, por la veracidad científica que son capaces de parecer demostrar, tiene el efecto de aproximar los artículos a un registro más científico.

En el caso de las imágenes satelitales, debemos señalar que son reconocidas como imágenes del territorio precisas y racionales, y por ello han sido utilizadas como un medio privilegiado para entender los impactos de las actividades sociales sobre la Tierra (Cosgrove et al, 2010). Sin embargo, la reciente difusión de softwares amigables como Google Earth, ha tenido al menos dos efectos que merecen ser señalados: por un lado, la creciente familiarización con este género de imágenes; por otro, la supresión en el imaginario de que su producción, tratamiento e interpretación comprende, como lo destaca Ricardo Castillo (2009), una serie de dimensiones sensoriales, sintáctica y semántica de gran complejidad con incidencia directa en la imagen que vemos y en lo que podemos mirar a través de ella.

En uno de los artículos dedicados al cambio climático, Viva publica seis imágenes satelitales de fragmentos del territorio: algunas ofrecen una mirada fugaz no periódica (Cazetta, 2009) que acompaña una fotografía; otras ofrecen una mirada fugaz periódica (Cazetta, 2009) como en el caso de la Figura 3. En Viva no encontramos imágenes de satélites meteorológicos que, por el contrario, son muy frecuentes en los programas de televisión para hacer visible el cambio climático (Lester et al, 2009). Sólo se han incorporado imágenes de satelitales de observación terrestre para mostrar los efectos visibles sobre el territorio (y no sobre las distintas capas de la atmósfera).

Según la información que presenta la revista, la Figura 3 comprende una secuencia de imágenes satelitales del mismo territorio capturadas en cuatro años diferentes. El texto que acompaña la serie de imágenes brinda dos informaciones: localización de la zona de captura -sur de la provincia de Santa Fe- y proceso registrado -el aumento del tamaño de una laguna-. Las imágenes satelitales, al igual que las fotografías, muestran efectos y no las causas: en el caso de la Figura 3, la serie de imágenes satelitales deja ver el aumento del tamaño de una laguna.

Figura 3: Hacer ver el cambio climático desde el aire: la utilización de imágenes satelitales

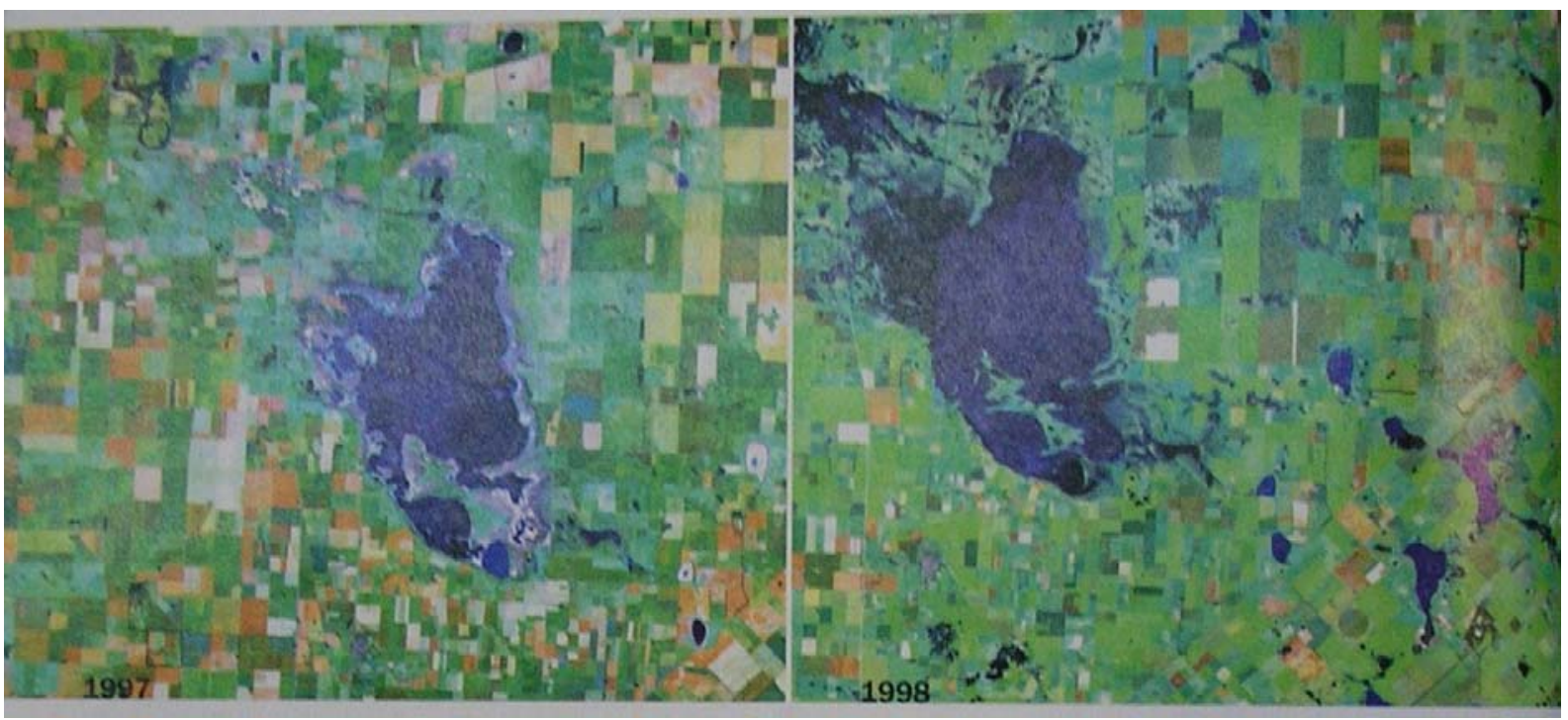

Publicado en formato digital: Dra. Verónica Hollman. PROBLEMAS EN TORNO A LA VISUALIZACIÓN DE LA CUESTIÓN AMBIENTAL EN MEDIOS DE CIRCULACIÓN MASIVA: Las Imágenes del Cambio Climático en la Revista Viva (1994-2010). Revista Geográfica Digital. IGUNNE. Facultad de Humanidades. UNNE. Año 10. № 19. Enero - Junio 2013. ISSN 1668-5180 Resistencia, Chaco. En:

http://hum.unne.edu.ar/revistas/geoweb/default.htm 


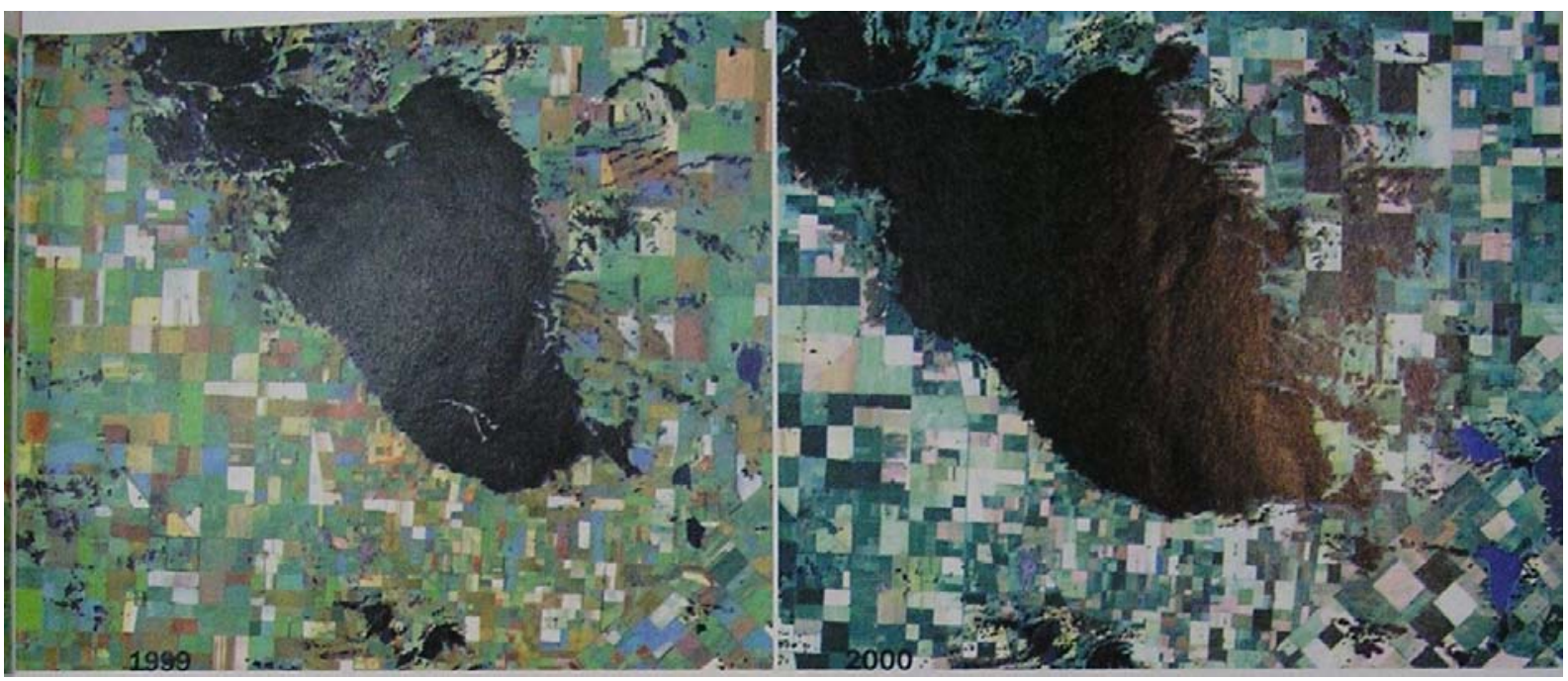

Fuente: "Argentina, ¿un país tropical?" Viva 9 Septiembre 2001. Gentileza Hemeroteca Biblioteca Nacional.

¿Por qué se apela a estas imágenes? ¿Qué se espera de ellas al seleccionarlas en una revista como esta? En este caso, las imágenes satelitales se utilizan para hacer ver posibles escenarios futuros para el territorio argentino señalados en el texto como escenarios reales: el aumento de las precipitaciones en la región pampeana y en el nordeste; la desertificación en el norte de la Patagonia y el aumento de las temperaturas en el noroeste argentino. Al igual que las fotografías, las imágenes satelitales nos hacen mirar un escenario actual como futuro y a la vez, un escenario posible como real. Sin embargo, las imágenes satelitales no resultan tan transparentes como las fotografías y se revelan ante nuestros ojos con un mayor grado de cientificidad. Como consecuencia, el lector que no logra mirar en la imagen satelital el efecto del cambio climático señalado en el artículo puede imaginar que esto obedece exclusivamente a un desconocimiento de las claves para interpretarlo y no a un problema de la propia imagen para capturar el fenómeno en cuestión.

Una temática ambiental de escala global podría provocar la sensación

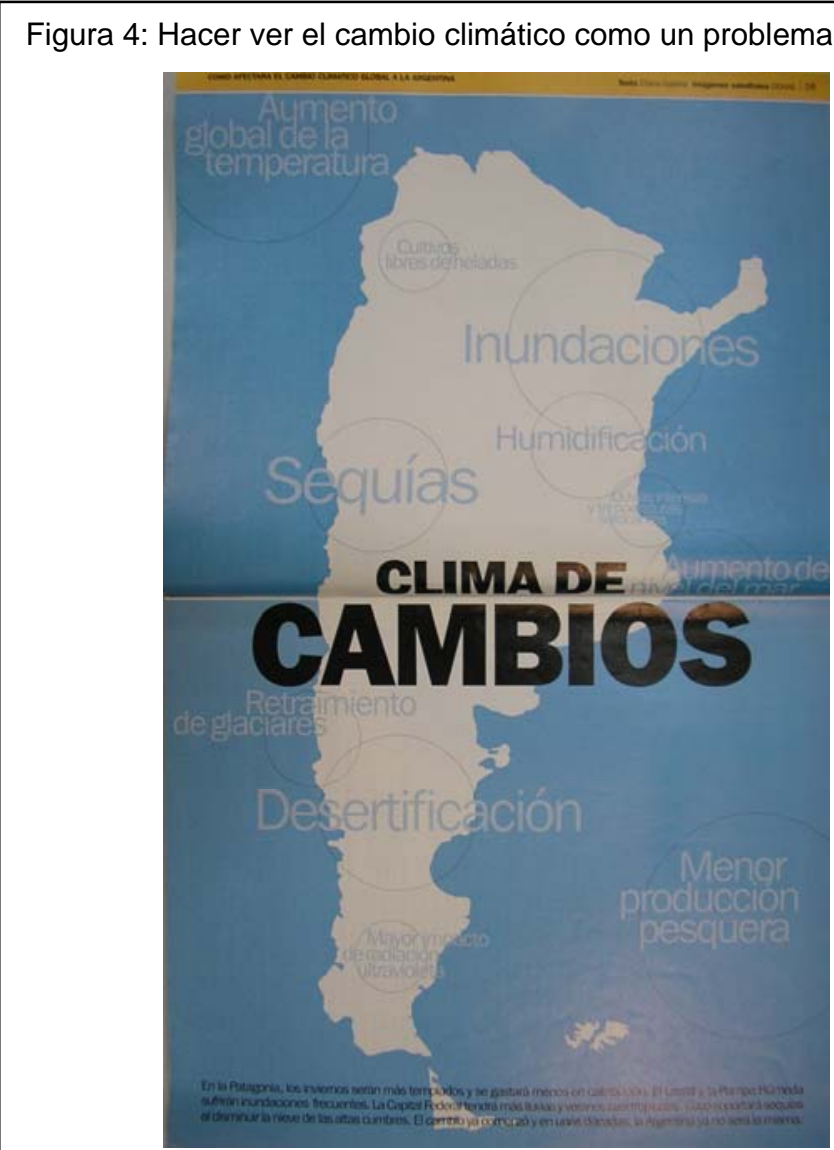

Fuente: "Argentina, ¿un país tropical?" Viva 9 Septiembre 2001. Gentileza Hemeroteca Biblioteca Nacional.

Publicado en formato digital: Dra. Verónica Hollman. PROBLEMAS EN TORNO A LA VISUALIZACIÓN DE LA CUESTIÓN AMBIENTAL EN MEDIOS DE CIRCULACIÓN MASIVA: Las Imágenes del Cambio Climático en la Revista Viva (1994-2010). Revista Geográfica Digital. IGUNNE. Facultad de Humanidades. UNNE. Año 10. № 19. Enero - Junio 2013. ISSN 1668-5180 Resistencia, Chaco. En:

http://hum.unne.edu.ar/revistas/geoweb/default.htm 
Revista Geográfica Digital. IGUNNE. Facultad de Humanidades. UNNE. Año 10. № 19. Enero - Junio 2013.

ISSN 1668-5180 Resistencia, Chaco

de que los efectos no nos afectarán directamente. Viva apela a la elocuencia del mapa para hacer ver que el cambio climático también tendrá incidencia en Argentina: en una silueta cartográfica, publicada a doble página, se indican y localizan los posibles efectos del cambio climático en distintas partes (Ver Figura 4).

El mapa se percibe desde el sentido común "como un objeto técnico y altamente especializado, tal vez un lenguaje cifrado" (Lois, 2009). Esto lo convierte en una imagen del territorio que, por su carácter técnico, es escasamente cuestionada. Analicemos cómo opera esta cualidad del mapa en la visualización del cambio climático.

La función de este mapa en el artículo no se limita a la localización: los posibles efectos del cambio climático se inscriben en círculos indicando precisión, exactitud y autoridad. En efecto, registrar en un mapa los hipotéticos efectos del cambio climático los reviste de un carácter científico y los convierte en un hecho real. El mapa, como advierte Denis Wood, convierte una proposición en un hecho (Wood, 1992). Pero también, el mapa nos ofrece "una realidad que excede nuestra visión, nuestro alcance, [...] una realidad a la que no accedemos por otros caminos" (Wood, 1992 citado en Lois, 2009). En este sentido, mapear los efectos del cambio climático nos hace ver algo que también excede nuestra visión desde la escala geográfica -efectos locales y regionales de un fenómeno global- y la escala temporal -efectos en un tiempo futuro que todavía no podemos visualizar-. El mapa nos persuade, nos hace ver algo que no podríamos ver en forma directa: los efectos del cambio climático en el tiempo presente y en el territorio nacional.

Finalmente, podríamos pensar que la selección de esta imagen se conecta con uno de los poderes del mapa, como nos invita a pensar en su sugerente artículo Carla Lois: "lo primero que hacemos ante un mapa es conectar esa imagen con lo que sabemos y aprendimos previamente, activar la memoria" (Lois, 2009). Si los títulos escritos en cada círculo activan en nuestra memoria visual las escenas dramáticas capturadas por las fotografías y filmaciones de catástrofes climáticas, el mapa activa nuestro sentido común geográfico: por ejemplo el color blanco homogeniza todo el territorio nacional y lo muestra como una unidad, los territorios contiguos (no solo el mar) quedan homogeneizados con el color celeste (como si fueran parte del territorio nacional), la inclusión de las islas Malvinas como apéndice del territorio nacional. El mapa activa el sentido nacional apelando a una serie de claves cartográficas que estamos entrenados a mirar y de este modo, nos hace ver que también nosotros, <los argentinos>, podremos padecer los efectos de un fenómeno global.

\section{ALGUNAS CONCLUSIONES PARA RE-PENSAR LA COMUNICACIÓN VISUAL DE LA CUESTIÓN AMBIENTAL}

¿Cómo hacer ver lo que carece de huella visible y es inimaginable? Gérard Wajcman, 2001: 10

El análisis de las imágenes del cambio climático puestas en circulación a través de una revista como Viva abre interesantes caminos en la indagación de las formas de comunicación visual de los temas ambientales y su efectividad. En primer lugar, encontramos que las imágenes seleccionadas para hacer ver el cambio climático se orientan a la visualización de sus efectos y no de sus causas. Sin embargo, tanto los efectos como las causas del cambio climático constituyen escenarios hipotéticos en los que predominan las controversias sobre las certezas-. Podríamos sugerir, entonces, que esta modalidad de dar a ver el cambio climático se orienta a provocar un impacto en las audiencias y promover una acción, un compromiso personal/colectivo. Pareciera prevalecer el supuesto de que el espanto es la emoción que necesariamente nos implica o involucra en una causa. Pero también, como analiza Sontag (2003), el dolor nos puede convertir en espectadores distantes. Esta posibilidad no es un dato menor a la hora de pensar las formas de comunicación de la temática ambiental desde los medios de comunicación, las propias organizaciones ambientales y las disciplinas escolares.

Publicado en formato digital: Dra. Verónica Hollman. PROBLEMAS EN TORNO A LA VISUALIZACIÓN DE LA CUESTIÓN AMBIENTAL EN MEDIOS DE CIRCULACIÓN MASIVA: Las Imágenes del Cambio Climático en la Revista Viva (1994-2010). Revista Geográfica Digital. IGUNNE. Facultad de Humanidades. UNNE. Año 10. № 19. Enero - Junio 2013. ISSN 1668-5180 Resistencia, Chaco. En:

http://hum.unne.edu.ar/revistas/geoweb/default.htm 
Revista Geográfica Digital. IGUNNE. Facultad de Humanidades. UNNE. Año 10. № 19. Enero - Junio 2013.

ISSN 1668-5180 Resistencia, Chaco

En segundo lugar, las imágenes ambientales no solo registran y documentan los efectos negativos de la transformación social de la naturaleza. Este trabajo sugiere que las imágenes moldean nuestro modo de mirar la naturaleza y de relacionarnos con ella; todavía más si se trata de imágenes de circulación masiva como las que hemos examinado en este artículo. Los tres géneros de imágenes utilizados en Viva -fotografías, imágenes satelitales y mapas- nos hacen ver escenarios hipotéticos como reales. El realismo, en el caso de las fotografías, y el carácter técnico, en el caso de los mapas y las imágenes satelitales tienen dos efectos directos en las audiencias. Por un lado, inscriben las imágenes en un registro de credibilidad. Por otro, terminan borrando cualquier duda o controversia enunciada en los textos de los artículos.

Sostenemos que las formas de hacer ver el cambio climático que se despliegan en Viva evidencian algunas problemáticas en torno a su visualización y a la búsqueda de una acción preventiva. Si centrar la comunicación visual en las causas del cambio climático implica hacer ver una relación que no ha podido ser efectivamente demostrada, orientar la comunicación visual a través de sus efectos también guarda la complejidad de hacer presente visualmente un escenario futuro. En este sentido, los géneros de imágenes seleccionados resultan efectivos para mostrar como actual un tiempo futuro y como real un escenario posible. Sin embargo, esta orientación visual hacia los efectos así como los géneros de imágenes escogidos plantean un dilema en cuanto a los impactos producidos en las audiencias. Por un lado, al orientar la visualización en los efectos, las imágenes obstaculizan mirar el cambio climático desde una perspectiva política, económica y cultural. Por otro lado, al hacer presente un posible futuro, las imágenes seleccionadas nos hacen mirar que el cambio climático ya sucedió (9). Entonces los lectores podrían preguntarse, ¿qué sentido tiene hacer algo hoy si ya sucedió? En otras palabras, el conjunto de imágenes y los modos de mirar construidos a partir de ellas podrían conducirnos a la inacción.

Si bien en el epígrafe de esta sección el inimaginable, al cual hace referencia el psicoanalista Gérard Wajcman es la Shoah, creemos que este interrogante también podría pensarse en torno a la comunicación visual del cambio climático, en particular, y de la cuestión ambiental en general. ¿Cómo hacer ver un escenario futuro, inimaginable, hipotético? ¿Cómo mostrar y comunicar lo que no se puede ver: el cambio climático, la contaminación de una cuenca hídrica, los perjuicios en la salud y calidad de vida de la población, etcétera? Sin duda, la comunicación visual de los temas ambientales nos invita a producir nuevas imágenes que, como indica Wajcman, "permitan inscribir legiblemente la mirada en la densidad de un acto" (Wacjman, 2001: 205). Precisamos imágenes que no limiten nuestros modos de imaginar otras modalidades de relacionarnos con la naturaleza (10), imágenes que nos acerquen con creatividad e imaginación a una perspectiva más política, económica y cultural de la cuestión ambiental (11). Pero también necesitamos nuevas formas de mirar las imágenes y aquí se vuelve inevitable referirnos a la educación visual. Desde la educación formal y no formal es necesario promover espacios en los cuales se desarrollen estrategias orientadas a prácticas de encuentro con las imágenes. Prácticas que conecten las imágenes con nuestros imaginarios geográficos, los cuestionen y enriquezcan. Se presenta así un convite para abrir posibles diálogos entre géneros de imágenes y espacios de educación visual, ya no con el ideal de dar a ver todo, sino con la finalidad de ofrecer perspectivas variadas y múltiples de las ideas que queremos comunicar. Sin duda, la geografía - en todos sus niveles de enseñanza- puede realizar interesantes contribuciones para que, como ciudadanos, contemos con más herramientas para emprender la aventura de mirar imágenes y entenderlas como discursos visuales del mundo.

\section{NOTAS}

(1) Tal vez uno de los trabajos más sugerentes es el ensayo del geógrafo Denis Cosgrove quien postula que una serie de imágenes -las fotografías de la Tierra tomadas en los viajes a la luna entre 1968-1972- han permitido construir la mirada de la tierra como organismo vivo y, por consiguiente, regido por las leyes de un orden biológico (Cosgrove, 1994). Es decir, la posibilidad de contar con

Publicado en formato digital: Dra. Verónica Hollman. PROBLEMAS EN TORNO A LA VISUALIZACIÓN DE LA CUESTIÓN AMBIENTAL EN MEDIOS DE CIRCULACIÓN MASIVA: Las Imágenes del Cambio Climático en la Revista Viva (1994-2010). Revista Geográfica Digital. IGUNNE. Facultad de Humanidades. UNNE. Año 10. № 19. Enero - Junio 2013. ISSN 1668-5180 Resistencia, Chaco. En:

http://hum.unne.edu.ar/revistas/geoweb/default.htm 
otras imágenes de la Tierra implicó una ruptura en su visualidad: desde una visión geométrica característica en el período comprendido entre mediados del siglo XV y mediados del siglo XX- a una visón orgánica y biológica -en la primera década del tercer milenio-. Con posterioridad a la captura y la difusión de estas imágenes de la tierra, se aprobaron las primeras leyes ambientales, se estableció el día de la tierra y se comenzaron a celebrar conferencias internacionales sobre medio ambiente, entre otras acciones.

(2) Los saberes y prácticas geográficas "no académicas" reconocen saberes geográficos sensu lato, es decir, no necesariamente producidos por geógrafos y transmitidos a través de vertientes tales como los medios de prensa, las guías de viajeros, las publicidades, Internet, etc.

(3) "Vivir con la autopista" Viva 19 Junio 1994; "Oíd mortales" Viva 24 Julio 1994; "Cenizas quedan" Viva 25 Septiembre 1994; "Calle cortada" 9 Octubre 1994; "Malos aires" 16 Octubre 1994; "Dock Sud" Viva 30 Abril 1995; "El camino de la basura" Viva 30 de Julio 1995; "Salven al río" Viva 24 Septiembre 1995.

(4) "Argentina, ¿Un país tropical?" Viva 9 Septiembre 2001; “A fuego lento" Viva 25 Febrero 2007.

(5) El investigador Spencer Weart dedica la totalidad de un capítulo para detallar un conjunto de evidencias visibles sobre el calentamiento global. Al finalizar el capítulo, no obstante termina explicando que "el único cambio climático global cuya causa ha sido observada científicamente por el ser humano" (Weart, 2003: 110) se produjo en Marte en 1971 como consecuencia de la puesta en órbita de la nave espacial Mariner.

(6) "Los caprichos del niño" Viva 4 Enero 1998; "La corriente del niño hace lo que quiere" Viva 17 Mayo 1998; "El año que vivimos" Viva 30 Diciembre 2001; "Vientos de cambio" Viva 12 Diciembre 2004; "El horror después de Katrina" Viva 18 Septiembre 2005; "A un año del tsunami, despertando a la vida" Viva 24 Diciembre 2005.

(7) Cada vez es más frecuente que los canales de televisión inviten a sus espectadores a convertirse en corresponsales vía la captura y envío de imágenes "caseras" de eventos climáticos extremos.

(8) "Argentina ¿un país tropical?" Viva 9 Septiembre 2001.

(9) Véase el análisis de Doyle (2009) sobre la utilización por Greenpeace de fotografías de la retracción de glaciares como prueba del cambio climático.

(10) Véase la publicación Weather report: cambio climático y artes visuales, que recopila las propuestas de 13 fotógrafos para mostrar el cambio climático desde el arte.

(11) Sobre las posibilidades que ofrece el humor gráfico para acercar la educación ambiental hacia una perspectiva más política, económica y cultural véase Hollman (2012).

\section{REFERENCIAS CITADAS}

Anderson, A. 1997. Media, culture and the environment. Rutgers University Press. New Jersey.

Arfuch, L. 2006. Las subjetividades en la era de la imagen: de la responsabilidad de la mirada. En I. Dussel \& D. Gutierrez (Eds.), Educar la mirada: políticas y pedagogías de la imagen: 75-84. Manantial. Buenos Aires.

Publicado en formato digital: Dra. Verónica Hollman. PROBLEMAS EN TORNO A LA VISUALIZACIÓN DE LA CUESTIÓN AMBIENTAL EN MEDIOS DE CIRCULACIÓN MASIVA: Las Imágenes del Cambio Climático en la Revista Viva (1994-2010). Revista Geográfica Digital. IGUNNE. Facultad de Humanidades. UNNE. Año 10. № 19. Enero - Junio 2013. ISSN 1668-5180 Resistencia, Chaco. En:

http://hum.unne.edu.ar/revistas/geoweb/default.htm 
Castillo, R. 2009. A imagen de satélite: do técnico ao político na construção do espaço geográfico. En: Pro-posiçoes, Vol 20, N 3 (60) Dossié A educação pelas imagens e suas geografias: 61-70. Unicamp. Campinas.

Cazetta, V. 2009. O estatus de realidade nas fotografias aéreas verticais no contexto dos estudos geográficos. En: Pro-posiçoes, Vol 20, N 3 (60) Dossié A educação pelas imagens e suas geografias: 71-86. Unicamp. Campinas.

Cosgrove, D. 1994. Contested Global Visions: One-World, Whole-Earth, and the Apollo Space Photographs. En: Annals of the Association of American Geographers, Vol. 84, No. 2 (Jun., 1994): 270-294.

Cosgrove, D. y Fox, W. 2010. Photography and Flight. Reaktion books. China.

Cronon, W. 1996. Beginnings. Introduction: In search of nature. En: W. Cronon (Ed.) Uncommon ground: 23-56. Norton \& Company. New York.

Doyle, J. 2009. Seeing the climate? The problematic status of visual evidence in climate change campaigning. En: Sidney Dobrin y Sean Moren (Ed). Ecosee: 279-298. State University of New York. New York.

Harvey, D. 1996. Justice, nature and the geography of difference. Blacwell. Oxford.

Hollman, V. 2012. El Humor gráfico y la educación de la mirada ambiental. En: Revista Sociedade \& Natureza. V24 N2, p. 227-242. Universidade Federal Uberlândia. Accesible en: http://www.seer.ufu.br/index.php/sociedadenatureza

Lester, L. y Cottle S. 2009. Visualizing climate change: television news and ecological citizenship. En: International Journal of Communication, 3: 920-936.

Lois, C. 2009. Imagen cartográfica e imaginarios geográficos. Los lugares y las formas de los mapas en nuestra cultura visual. En: Scripta Nova. Revista Electrónica de Geografía y Ciencias Sociales. Universidad de Barcelona. Barcelona, 1 de septiembre de 2009, vol. XIII, núm. 298<http://www.ub.es/geocrit/sn/sn-298.htm>

Oliveira Júnior, W. 2009. Grafar o espaço, educar os olhos. Rumo a geografias menores. En: Pro-posiçoes, Vol 20, N 3 (60) Dossié A educação pelas imagens e suas geografias: 17-28. Unicamp. Campinas.

Portogonçalves, C. 1990. Os (des) caminhos do meio ambiente. Contexto. Sao Paulo.

Rodríguez Fominaya. A. 2007. Weather report: cambio climático y artes visuales. Textos, concepto y diseño de Álvaro. Centro Atlántico de Arte Moderno. Las Palmas de Gran Canaria.

Santos, M. 1996. A natureza do espaço. Hucitec. Sao Paulo.

Sontag, S. 2003. Ante el dolor de los demás. Alfaguara. Buenos Aires.

Wajcman, G. 2001. El objeto del siglo. Amorrortu. Buenos Aires.

Publicado en formato digital: Dra. Verónica Hollman. PROBLEMAS EN TORNO A LA VISUALIZACIÓN DE LA CUESTIÓN AMBIENTAL EN MEDIOS DE CIRCULACIÓN MASIVA: Las Imágenes del Cambio Climático en la Revista Viva (1994-2010). Revista Geográfica Digital. IGUNNE. Facultad de Humanidades. UNNE. Año 10. № 19. Enero - Junio 2013. ISSN 1668-5180 Resistencia, Chaco. En:

http://hum.unne.edu.ar/revistas/geoweb/default.htm 
Weart, S. 2003. Una amenaza visible. En: Weart S. El calentamiento global: 85-110. Pamplona. Editorial Laetoli.

Williams, R. 1980. Ideas of nature. En: Raymond W. Problems in Materialism and Culture: 68-85. Verso. Londres.

Publicado en formato digital: Dra. Verónica Hollman. PROBLEMAS EN TORNO A LA VISUALIZACIÓN DE LA CUESTIÓN AMBIENTAL EN MEDIOS DE CIRCULACIÓN MASIVA: Las Imágenes del Cambio Climático en la Revista Viva (1994-2010). Revista Geográfica Digital. IGUNNE. Facultad de Humanidades. UNNE. Año 10. № 19. Enero - Junio 2013. ISSN 1668-5180 Resistencia, Chaco. En:

http://hum.unne.edu.ar/revistas/geoweb/default.htm 